\title{
Efeitos da inundação no crescimento, trocas gasosas e porosidade radicular da carnaúba (Copernicia prunifera (Mill.) H.E. Moore)
}

\author{
Giovana Maria Tadaieski Arruda ${ }^{1}$ e Maria Elisa Ribeiro Calbo ${ }^{1}$
}

Recebido em 06/05/2002. Aceito em 13/08/2003

\begin{abstract}
RESUMO - (Efeitos da inundação no crescimento, trocas gasosas e porosidade radicular da carnaúba (Copernicia prunifera (Mill.) H.E. Moore). A carnaúba, Copernicia prunifera (Mill.) H.E. Moore, é uma palmeira típica do Nordeste brasileiro, ocorrendo com frequiência em terrenos salinizados e mal drenados. Para se determinar o grau de tolerância da carnaúba à inundação, plantas com quatro meses de idade foram mantidas em vasos com o solo coberto por uma lâmina de $80 \mathrm{~mm}$ de água além de um grupo controle. A altura da parte aérea dessas plantas foi medida semanalmente durante 60 dias de inundação, após tal período, quantificaram-se os volumes gasosos intercelulares das raízes (porosidade). A porosidade das raízes teve valores de $25,3 \%$ em plantas inundadas e 21,8\% em plantas controle. As taxas de fotossíntese, condutância estomática e transpiração foram determinadas semanalmente, durante 35 dias de inundação, para plantas com 10 meses de idade. Após o período de inundação de 35 dias, as concentrações de $\mathrm{CO}_{2}$ e $\mathrm{O}_{2}$ nas raízes das plantas foram quantificadas, sendo observada aumento da concentração de $\mathrm{CO}_{2}$ e diminuição da concentração de $\mathrm{O}_{2}$ em raízes de plantas inundadas, comparadas às concentrações desses gases em plantas controle. $\mathrm{O}$ alagamento do solo reduziu a fotossíntese e a condutância estomática, mas não afetou o crescimento da parte aérea e nem induziu o aparecimento de sintomas resultantes do estresse de inundação, indicando que a carnaúba apresenta alguma tolerância a tal condição, conferida possivelmente pela alta porosidade das raízes.
\end{abstract}

Palavras-chave: condutâcia estomática, Copernicia prunifera (Mill.) H.E. Moore, estresse por inundação, hipoxia, palmeiras

\begin{abstract}
Effects of flooding on carnaúba growth, gas exchange and root porosity (Copernicia prunifera (Mill.) H.E. Moore). Carnaúba, Copernicia prunifera (Mill.) H.E. Moore, is a common Brazilian palm from the Northeast region, which is usually found in saline and poorly drained soils. To evaluate the degree of tolerance to flooding, 4 month-old plants were grown in soil submerged by a $80 \mathrm{~mm}$ water layer, for 60 days. During this period, shoot height was measured weekly. After 60 days of flooding, root intercellular air volume (porosity) was measured. Porosity was $25,3 \%$ on flooded plants and $21,8 \%$ on control plants. Photosynthetic rate, stomatal conductance and transpiration were measured in 10 month-old plants, during 35 days of flooding. After this period of flooding, internal $\mathrm{CO}_{2}$ and $\mathrm{O}_{2}$ concentrations were quantified on roots. Flooded plants had higher concentration of $\mathrm{CO}_{2}$, and lower concentration of $\mathrm{O}_{2}$, compared to control plants. While a reduction in photosynthesis and stomatal conductance occurred, shoot height improvement was not affected and no visible flooding symptoms were seen in carnaúba shoots, indicating that this species displays tolerance to flooding, which is probably related to the high root porosity.
\end{abstract}

Key words: stomatal conductance, Copernicia prunifera (Mill.) H.E. Moore, flooding stress, hypoxia, palm trees

\section{Introdução}

A carnaúba, Copernicia prunifera (Mill.) H.E. Moore, é uma palmeira que atinge 10 a $15 \mathrm{~m}$ de altura e 15 a $25 \mathrm{~cm}$ de diâmetro (Henderson et al. 1995). Além do grande potencial paisagístico, possui celulose de qualidade superior para fabricação de papel e sua madeira é empregada para diversos usos. As folhas, depois de secas e retirada a cera, que é utilizada na indústria, são usadas na confecção de esteiras, chapéus e outros artefatos.

Típica do Nordeste brasileiro a carnaúba é um dos suportes da economia dos Estados do Piauí, Ceará, Rio Grande do Norte e Maranhão, sendo encontrada também na Bahia, em Alagoas e em Sergipe (Lorenzi et al. 1996). A maior concentração de carnaubais se encontra nos vales dos rios do Nordeste, que muitas vezes formam extensas planícies inundáveis. Estas áreas podem permanecer inundadas por alguns meses do ano e, posteriormente, chegam a ser submetidas ao estresse de falta de água nos meses mais secos. A ocorrência periódica da inundação nos carnaubais dos vales dos rios indica que a carnaúba deva apresentar adaptações para suportar a diminuição do oxigênio no solo. O buriti, por exemplo, desenvolve pneumatóforos após a inundação do solo (Calbo et al. 1998), e o açaí forma raízes adventícias próximas à superfície da água de inundação (Costa \& Calbo 1999).

\footnotetext{
1 Departamento de Botânica, Universidade de Brasília, C. Postal 04457, CEP 70919-970, Brasília, DF, Brasil Autor para correspondência: giovana @unb.br
} 
A presença de grandes volumes gasosos intercelulares no parênquima cortical da raiz tem sido observada em espécies adaptadas a locais inundados. Estes volumes gasosos facilitam o transporte de oxigênio da parte aérea para a raiz e reduzem a hipoxia nas raízes, principal causa de distúrbios fisiológicos que podem ocorrer em plantas de locais inundados (Drew 1983; Smirnoff \& Crawford 1983; Justin \& Armstrong 1987; Lobo \& Joly 1995; Pimenta et al. 1998; Bacanamwo \& Purcell 1999).

As espécies sensíveis ao estresse de inundação desenvolvem sintomas, os quais resultam principalmente de distúrbios causados pela hipoxia ou anoxia nas raízes. Os mais comuns são a abscisão de folhas, flores e frutos, clorose nas folhas, redução no comprimento da raiz principal, redução no crescimento em altura, inibição da formação de primórdios foliares, redução na expansão foliar e até mesmo morte da planta (Kozlowski 1984; Drew 1983, 1997; Sing et al. 1991; Marques et al. 1996; Lizaso et al. 2001).

Além de adaptações morfo-anatômicas, podem ocorrer algumas alterações nas taxas de transpiração, de fotossíntese e na condutância estomática, decorrentes de ajustes bioquímicos e metabólicos, provocados pela inundação (Reid \& Bradford 1984; Kozlowski 1997). A manutenção de uma alta taxa de fotossíntese sob inundação foi usada como critério para diferenciar cultivares mais tolerantes à inundação na espécie arbórea Acer rubrum L. (Anella \& Wihtlow 1999). O buriti, por exemplo, que é uma espécie adaptada a locais inundados, não apresentou redução significativa da fotossíntese durante 36 dias de inundação (Calbo et al. 1998).

Apesar de muitas espécies da família Palmae serem tolerantes ao estresse de inundação, os estudos de fisiologia de palmeiras são escassos, principalmente no que diz respeito aos mecanismos de tolerância a esta condição. Considerando que a carnaúba tem como hábitat locais sujeitos a inundações periódicas (Henderson et al. 1995), supõe-se que ela possua adaptações morfológicas, anatômicas ou fisiológicas que minimizariam a falta de oxigênio nas raízes inundadas e manteriam a assimilação de $\mathrm{O}_{2}$ no período de inundação.

O objetivo deste trabalho foi avaliar o grau de tolerância da $C$. prunifera (Mill.) H.E. Moore à inundação, considerando os efeitos desta sobre as trocas gasosas, a condutância estomática e a porosidade de raízes, bem como seu efeito sobre a altura da parte aérea e eventual surgimento de adaptações morfológicas ou sintomas conseqüentes do estresse de inundação. Tais informações são importantes, pois contribuem para a compreensão da distribuição desta espécie nas planícies inundáveis do Nordeste do Brasil, servindo de apoio a projetos de conservação da espécie e destas fisionomias.

\section{Material e métodos}

Sementes de carnaúba provenientes do Ceará foram germinadas em copos plásticos perfurados contendo vermiculita e mantidas em câmara de crescimento com temperatura diurna de $25^{\circ} \mathrm{C}$ e noturna de $24^{\circ} \mathrm{C}$, sob fotoperíodo de 12 horas. Aos 30 dias de idade, as plântulas foram transplantadas para solo contido em sacos de polietileno preto perfurados, com capacidade de 7L e colocadas ao ar livre, sob condições naturais de temperatura e luminosidade, com duas irrigações diárias.

Aos quatro meses de idade, as plântulas foram aleatoriamente separadas, para o início do primeiro experimento, composto por dois tratamentos (plantas inundadas e plantas controle), com 10 repetições. As plantas controle foram mantidas nos sacos de polietileno com uma irrigação diária, enquanto que para as plântulas do tratamento inundado, os sacos de polietileno foram colocados em baldes plásticos de 20 litros mantendo-se o solo coberto por uma camada de água com cerca de $80 \mathrm{~mm}$ (para evitar a proliferação de algas, os baldes foram cobertos com plástico preto na altura da lâmina d'água). Durante 60 dias, o comprimento da parte aérea das plantas foi medido semanalmente, enquanto se observava o aparecimento de sintomas de estresse. Após os 60 dias de inundação, os volumes gasosos intercelulares das raízes (porosidade) foram medidos através do método de Jensen et al. (1969) modificado. A modificação foi a substituição do homogeinizador pela trituração da amostra em um almofariz, seguido da aplicação de vácuo para remoção da fase gasosa.

O segundo experimento foi realizado com plantas de carnaúba com 10 meses de idade, cultivadas nas mesmas condições do experimento anterior. Tais plantas foram usadas para determinação das taxas de fotossíntese, de condutância estomática e de transpiração, utilizando o analisador de gás por infravermelho da ADC/ Hoddeston, modelo LCA-4. As medidas foram feitas semanalmente, por um período de 35 dias, sempre no período da manhã, utilizando a folha mais madura de cada planta.

Após os 35 dias de inundação do segundo experimento, a concentração de gases dentro das raízes foi 
determinada através do método de Bonnier \& Mangin citado por Thoday (1913). A retirada de ar do tecido das raízes para determinação das concentrações de $\mathrm{CO}_{2}$ e $\mathrm{O}_{2}$ foi feita através da submissão das plantas ao vácuo; para isto completou-se um dessecador com água previamente fervida (para se proporcionar uma redução na concentração de oxigênio da água) e colocou-se dentro dele um funil invertido com seu orifício tampado por uma rolha de borracha, contendo a planta da qual se desejava retirar ar da raiz. O dessecador era tampado e submetido ao vácuo (1/10atm), com isto o gás da atmosfera interna expandiu, borbulhou para fora da raiz e ficou preso no funil, de onde foi retirado com seringa e agulha para medição.

Os resultados de todos os experimentos foram avaliados pelo teste de Tukey com 5\% de probabilidade, através do programa SAS.

\section{Resultados e discussão}

$\mathrm{O}$ aumento na altura da parte aérea das plantas de carnaúba não foi afetado pela inundação (Fig. 1), a exemplo do buriti, Mauritia vinifera Mart. (Calbo et al. 1998). As plantas também não apresentaram sintoma de estresse de inundação como clorose nas folhas, e não desenvolveram estruturas que pudessem facilitar a aeração das raízes, como pneumatóforos, raízes adventícias próximas à superfície do solo ou lenticelas hipertrofiadas. Genipa americana L. submetida à inundação por 60 dias, assim como a carnaúba, não apresentou diferenças na altura da parte aérea, além de não apresentar também modificações morfológicas (Andrade et al. 1999).

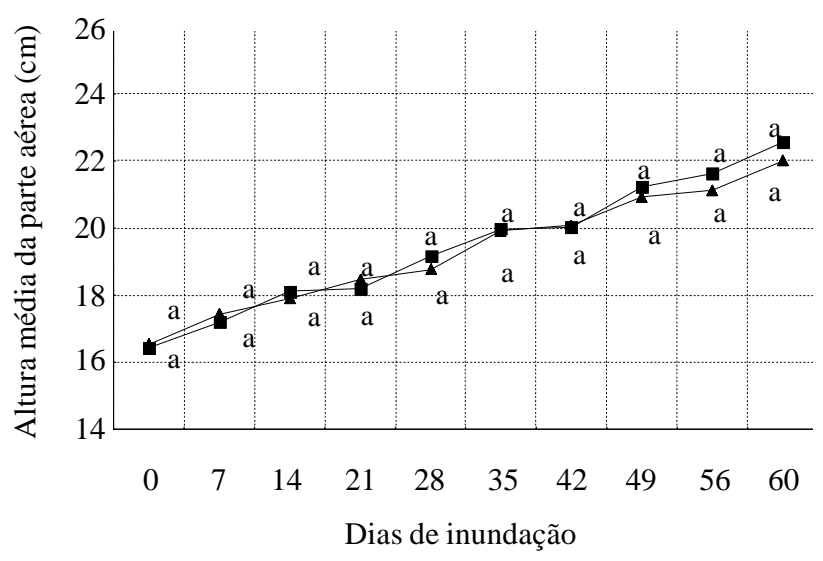

Figura 1. Crescimento médio de plantas de carnaúba, com quatro meses de idade, submetidas à inundação por 60 dias. Plantas controle; $\boldsymbol{\Delta}$ Plantas inundadas. Médias do mesmo dia, seguidas pela mesma letra, não diferem entre si pelo teste Tukey ao nível de 5\%.
A porosidade nas raízes de carnaúba aumentou com a inundação (Tab. 1). A porosidade foi alta e bem acima dos valores de porosidade de plantas sensíveis à inundação, as quais, segundo Justin \& Armstrong (1987), têm valores de porosidade inferiores a $5 \%$. Sminorff \& Crawford (1983) citaram que plantas adaptadas apresentam valores de porosidade maiores que $20 \%$, os quais são aumentados com a inundação. Em Lepidium latifolium L. (Chen et al. 2002), os valores de porosidade da ordem de $20 \%$ encontrados em plantas controle foram quase que duplicados após 50 dias de inundação. A alta porosidade das raízes de carnaúba, mesmo em plantas não expostas à inundação, indica que a formação do aerênquima é uma característica genética que se expressa mesmo sob aeração abundante. A presença de aerênquima muito desenvolvido foi comprovada também pela observação de cortes anatômicos da raiz feitos à mão livre (dados não apresentados). A porosidade relativamente alta das raízes comparada com a porosidade das raízes do tomateiro 6\% e das raízes do milho 7,6\% (Jensen et al. 1969) possivelmente facilitou o transporte de oxigênio da parte aérea para as raízes e conferiu certo grau de tolerância da carnaúba à inundação periódica, uma vez que a mesma não desenvolveu sintomas de injúria e não apresentou redução no incremento de altura da parte aérea.

Tabela 1. Percentagem de volumes gasosos intercelulares de raízes e folhas de carnaúba, com 4 meses de idade, mantidas sob inundação por 60 dias.

\begin{tabular}{ll}
\hline & Porosidade $(\%)$ \\
\hline Controle & $21,83 *( \pm 1,6)$ \\
Inundadas & $25,33 *( \pm 1,21)$ \\
\hline * Médias diferentes entre si, pelo teste Tukey ao nível de $5 \%$. \\
Números entre parênteses representam o desvio padrão da média.
\end{tabular}

Até o $28^{\circ}$ dia de tratamento, plantas inundadas e plantas controle não apresentaram diferenças significativas na condutância estomática (Fig. 2A). Já a transpiração não foi afetada em plantas inundadas (Fig. 2B) no $35^{\circ}$ dia de inundação. Espécies como Nyssa aquatica L. e Cephalantus occidentalis L., comuns em terrenos brejosos, também não apresentaram diferenças na condutância estomática e na taxa de transpiração, quando crescidas em solos alagados (McLeod et al. 1987). Em plantas com menor tolerância à inundação, como Gerbera jamesonii 

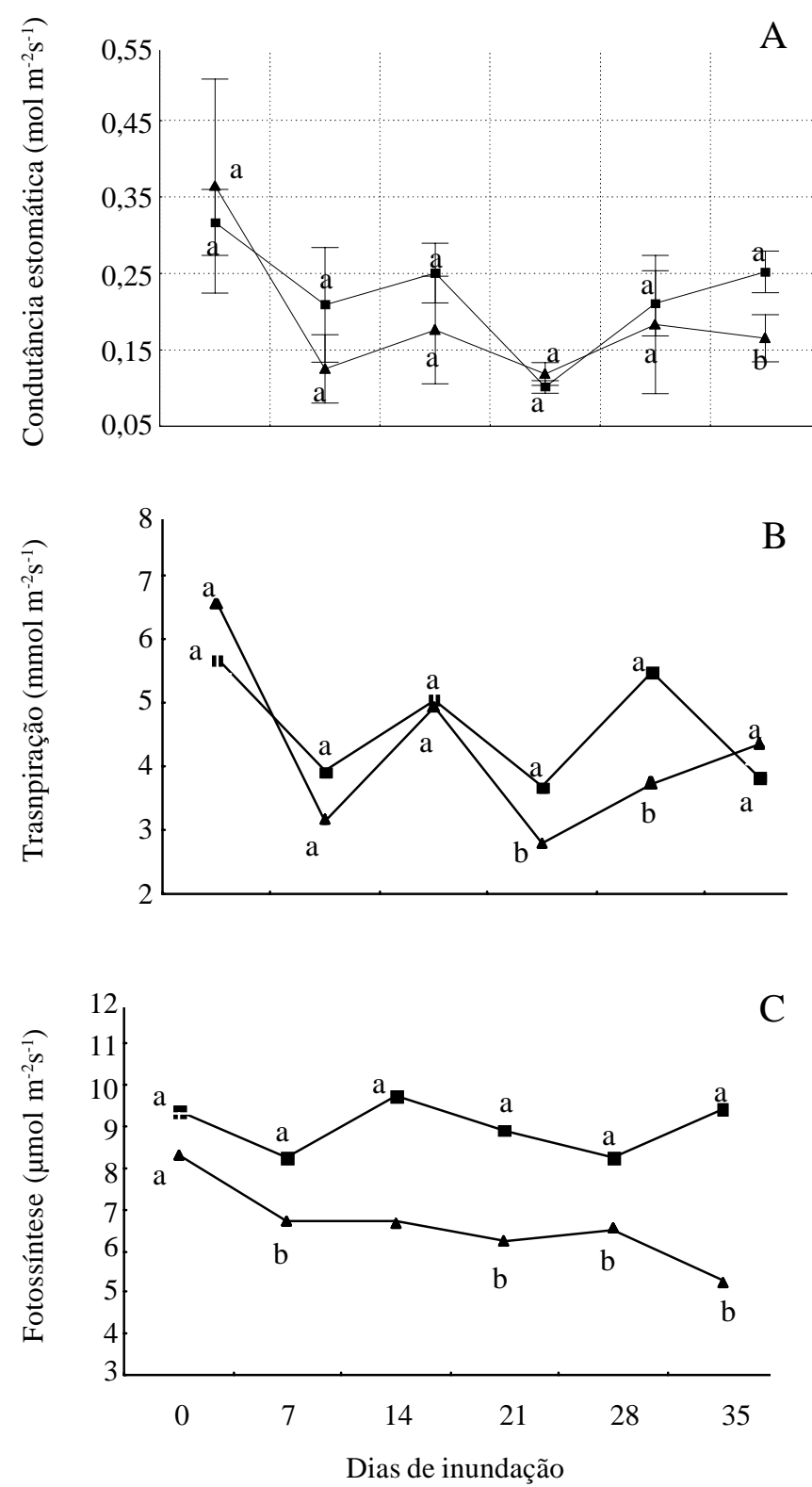

Figura 2. A. Condutância estomática, B. Transpiração, C. Fotossíntese de plantas de carnaúba com 10 meses de idade, submetidas à inundação por 35 dias. — Plantas controle; $\Delta$ Plantas inundadas. Médias do mesmo dia, seguidas pela mesma letra, não diferem entre si pelo teste Tukey ao nível de 5\%.

Adlam, tais parâmetros foram significativamente reduzidos em plantas inundadas, com apenas seis dias de tratamento (Olivella et al. 2000).

A partir da primeira semana de tratamento, a fotossíntese líquida (Fig. 2C) das plantas sob inundação apresentou redução quando comparada à fotossíntese líquida de plantas controle. Tais resultados assemelham-se aos obtidos para a maioria das espécies já estudadas (Bradford 1983; Pezeski 1994; Sing et al. 1991). As espécies do gênero Acer mais adaptadas à inundação tiveram valores de fotossíntese maiores que as não adaptadas (Anella \& Whitlow 1999). Na carnaúba, até o $28^{\circ}$ dia de tratamento, a inundação reduziu a taxa fotossintética, independentemente da condutâcia estomática (Fig. 2A e 2C). A redução na condutância estomática pode diminuir a taxa de fotossíntese, mas o estresse de inundação pode afetar diretamente o aparelho fotossintético, independentemente da condutância estomática, como foi observado em tomateiro. Nesta espécie, a inibição da fotossíntese não foi restaurada com elevadas concentrações de $\mathrm{CO}_{2}$ (Bradford 1983). A redução na regeneração da Rubisco (Bradford, 1983), a inibição da fotossíntese devida ao acúmulo de amido (Topa \& Cheeseman 1992) e a redução na atividade da Rubisco (Pezeski 1994) têm sido sugeridas como causas da redução da fotossíntese em plantas submetidas à inundação.

A concentração de $\mathrm{CO}_{2}$ em raízes inundadas (Tab. 2) aumentou e a de $\mathrm{O}_{2}$ diminuiu, quando comparadas tanto às concentrações destes gases no ar $(0,32 \%$ e $20,09 \%$ ), quanto às concentrações de $\mathrm{CO}_{2}$ e $\mathrm{O}_{2}$ de plantas controle. A difusão de $\mathrm{CO}_{2}$ foi menor nas raízes inundadas, o que era esperado, uma vez que a taxa de difusão de gases é mais lenta na água. Resultados semelhantes foram obtidos por Good \& Patrick (1987), com raízes de Fraxinus pennsylvanica Marshall, onde a concentração de $\mathrm{CO}_{2}$ foi $2,4 \%$ e a de $\mathrm{O}_{2} 20,0 \%$ em plantas drenadas e $10,4 \%$ e $14,1 \%$ respectivamente, em plantas inundadas. A concentração de $\mathrm{O}_{2}$, no entanto, não atingiu valores que pudessem resultar em hipoxia, indicando baixa resistência à difusão nas raízes mais grossas, o que foi causado pela alta porosidade (Tab. 1). Possivelmente, nas raízes mais finas esta concentração atinja valores bem menores que causem uma hipoxia capaz de alterar algumas funções fisiológicas das plantas, como, por exemplo, a diminuição da fotossíntese. A concentração destes gases não foi medida nestas raízes, devido à dificuldade de extrair amostras representativas em quantidade suficiente.

Tabela 2. Concentrações de $\mathrm{O}_{2}$ e $\mathrm{CO}_{2}$ em raízes de carnaúba, com 10 meses de idade, mantidas sob inundação por 35 dias.

$$
\begin{array}{cc}
\text { Concentração de } \mathrm{CO}_{2} & \text { Concentração de } \mathrm{O}_{2} \\
(\%) & (\%)
\end{array}
$$

$\begin{array}{lll}\text { Raízes controle } & 0,34^{*}( \pm 0,014) & 20,3 *( \pm 0,19) \\ \text { Raízes inundadas } & 0,85^{*}( \pm 0,011) & 17,7 *( \pm 0,16)\end{array}$

* Médias diferentes entre si, pelo teste Tukey ao nível de 5\% Números entre parênteses representam o desvio padrão da média. 
Os resultados obtidos neste trabalho, somados ao fato de carnaubais serem essencialmente encontrados em regiões de alagamento periódico, refletem a capacidade da carnaúba em tolerar a inundação. Uma vez que plantas inundadas não mostraram injúrias ou comprometimento do crescimento, quando comparadas a plantas controle, os altos valores de porosidade da raiz sugerem que o $\mathrm{O}_{2}$ seja captado pela parte aérea, via estômatos, até as raízes, diminuindo os efeitos causados pela hipoxia do solo.

No entanto, adaptações morfológicas e anatômicas, resultantes do estresse de inundação, podem estar relacionadas a aspectos fisiológicos, como o balanço hormonal. Olivella et al. (2000) reportam que ácido abscísico e citocinina podem funcionar como mensageiros da planta sob estresse, regulando a abertura estomática. A formação de aerênquima sob anerobiose, por exemplo, parece ser mediada pelo aumento das concentrações de etileno (Konings 1982; Bacanamwo \& Purcell 1999). Sendo assim, para conclusões mais definitivas sobre os mecanismos que permitem à $C$. prunifera (Mill.) H.E. Moore tolerar a inundação, estudos futuros devem ser realizados, buscando relacionar ajustes adaptativos com alterações hormonais.

\section{Referências bibliográficas}

Andrade, A.C.S.; Ramos, F.N.: Souza, A.F. Loureiro, M.B. \& Bastos, R. 1999. Flooding effects in seedlings of Cytharexyllum myrianthum Cham. and Genipa americana L.: responses of two neotropical lowland tree species. Revista Brasileira de Botânica 22: 281-285.

Anella, L.B. \& Whitlow, T.H. 1999. Flood-tolerance ranking of red Freeman aple cultivars. Journal of Arboriculture 25(1): 31-37.

Bacanamwo, M. \& Purcell, L.C. 1999. Soybean root morphological and anatomical traits associated with acclimatation to flooding. Crop Science 39: 143-149.

Bradford, K.J. 1983. Effects of soil flooding on leaf gas exchange of tomato plants. Plant Physiology 73: 475-479.

Calbo, M.E.R.; Moraes, J.P.V. \& Calbo, A.G. 1998. Crescimento, condutância estomática, fotossíntese e porosidade do buriti sob inundação. Revista Brasileira de Fisiologia Vegetal 10: 51-58.

Chen, H.; Qualls, R.G. \& Miller, G.N. 2002. Adaptative responses of Lepidium latifolium to soil flooding: biomass alocation, adventitious rooting, aerenchyma formation and ethylene production. Environmental and Experimental Botany 48: 119-128.

Costa, C.J. \& Calbo, M.E.R. 1999. Porosidade, fotossíntese, condutância estomática e transpiração do açaí sob inundação. Revista Brasileira de Fisiologia Vegetal. (Suplementos). p. 24.
Drew, M.C. 1983. Plant injury and adaptation to oxygen deficiency in the root environment: a review. Plant and Soil 75: 179-199.

Drew, M.C. 1997. Oxygen deficiency and root metabolism: Injury and acclimation under hypoxia and anoxia. Plant Physiology 48: 223-250.

Good, B.J. \& Patrick, J.W.H. 1987. Gas composition and respiration of water oak (Quercus nigra L.) and green ash (Fraxinus pennsylvanica Marsh.) roots after prolonged flooding. Plant and Soil 97: 419-427.

Henderson, A.; Galeano, G. \& Bernal, R. 1995. Palms of the Americas. Priceton, Princeton University Press, New Jersey.

Jensen, C.R.; Luxmoore, R.J.; Van Gundy, S.D. \& Stolzy, L.H. 1969. Root air space measurements by a picnometer method. Agronomy Journal 61: 474-475.

Justin, S.H.F.W. \& Armstrong, W. 1987. The anatomical characteristics of roots and plant response to soil flooding. New Phytologist 106: 465-495.

Konings, H. 1982. Ethylene-promoted formation of aerenchyma in seedling roots of Zea mays L. under aerated and non-aerated conditions. Physiologica Plantarum 54: 119-124.

Kozlowski, T.T. 1984. Responses of woody plants to flooding. Pp. 129-159. In: T.T. Kozlowski (ed.). Flooding and Plant Growth. Academic Press, San Diego.

Kozlowski, T.T. 1997. Responses of woody plants to flooding and salinity. Tree Physiology Monograph n.1.

Lizaso, J.I.; Melendez, L.M. \& Ramirez, R. 2001. Early flooding of two cultivars of tropical maize. i. shoot and root growth. Journal of Plant Nutrition 24(7): 979-995.

Lobo, P.C. \& Joly, C.A. 1995. Mecanismos de tolerância à inundação de plantas de Talauma ovata St. Hil. (Magnoliaceae), uma espécie típica de matas de brejo. Revista Brasileira de Botânica 18(2): 177-184.

Lorenzi, H.; Souza, H.M.; Costa, J.T.M.; Siqueira, L.S.C. \& Von Brehr, N. 1996. Palmeiras no Brasil - Nativas e Exóticas. Ed. Plantarum, Nova Odessa.

Marques, M.C.M.; Pimenta, J.A. \& Colli, S. 1996. Mecanismos de tolerância a inundação de Cedrela fissilis (Vell.) e Anadenanthera colubrina (Vell.) Bren. Submetidas a diferentes regimes hídricos. Arquivos de Biologia e Tecnologia 9(2): 385-392.

McLeod, K.W.; Donovan, L.A. \& Stumpff, N.J. 1987. Responses of woody seedlings to elevates flood water temperatures. Pp. 441-451. In: D.D. Hook, W.H. McKee, H.K. Smith, J. Gregory, V.G. Burrell, M.R. Devoe, R.E. Sojka, S. Gilbert, R. Banks, L.H. Stolzy, C. Brooks, T.D. Mattheus \& T.H. Shear (eds.). The ecology and management of wetlands. Portland, Timber Press.

Olivella, C.; Biel, C.; Vendrel, M. \& Savé, R. 2000. Hormonal and physiological responses of Gerbera jamesonii to flooding stress. HortScience 35(2): 222-225.

Pezeski, S.R. 1994. Responses of baldcypress (Taxodium distichum) seedlings to hypoxia: leaf protein content, ribulose-1,5-bisphosphate carboxilase/oxigenase activity and photosynthesis. Photosynthetica 30: 59-68. 
Pimenta, J.A.; Bianchini, E. \& Medri, M.E. 1998. Adaptation to flooding by tropical trees. Morphological and anatomical modifications. Pp. 157-156. In: F.R. Scarano, \& A.C. Franco (eds.). Ecophysiological strategies of xerophytic and amphibious plants in the neotropics. Series Oecologia Brasiliensis, v. IV. PPGE-UFRJ. Rio de Janeiro.

Reid, D.M. \& Bradford, K.J. 1984. Effects of flooding on hormonal relations. Pp. 195-219. In: T.T. Kozlowski (ed.). Flooding and plant growth. Academic Press, San Diego. Sing, A.B.P.; Tucker, K.A.; Sutton, J.D. \& Bhardwaj, H.L. 1991. Flooding reduced gas exchange in snap bean. HortScience 26: 372-373.
Smirnoff, N. \& Crawford, R.M.M. 1983. Variation in the structure and response to flooding of root aerenchyma in some wetland plants. Annals of Botany 51: 237-249.

Topa, M.A. \& Cheeseman J.M. 1992. Effects of root hypoxia and low $\mathrm{P}$ supply on relative growth, carbon dioxide exchange rates and carbon partitioning in Pinus serotina seedlings. Physiologia Plantarum 86: 136-144.

Thoday, M.A. 1913. On the capillary eudimetric apparatus of Bonnier and Mangin for analysis of air in investing the gases exchanges of plants. Annals of Botany 27: 565-573. 